\title{
Don't you dare look at me, or else: Negative and aggressive interpretation bias, callous unemotional traits and type of aggression.
}

Citation for published version (APA):

Cima - Knijff, M., Vancleef, L. M. G., Lobbestael, J., Meesters, C., \& Korebrits, A. (2014). Don't you dare look at me, or else: Negative and aggressive interpretation bias, callous unemotional traits and type of aggression. Journal of Child and Adolescent Behavior, 2(2). https://doi.org/10.4172/2375-4494.1000128

Document status and date:

Published: 01/01/2014

DOI:

10.4172/2375-4494.1000128

Document Version:

Publisher's PDF, also known as Version of record

Document license:

Taverne

Please check the document version of this publication:

- A submitted manuscript is the version of the article upon submission and before peer-review. There can be important differences between the submitted version and the official published version of record.

People interested in the research are advised to contact the author for the final version of the publication, or visit the DOI to the publisher's website.

- The final author version and the galley proof are versions of the publication after peer review.

- The final published version features the final layout of the paper including the volume, issue and page numbers.

Link to publication

\footnotetext{
General rights rights.

- You may freely distribute the URL identifying the publication in the public portal. please follow below link for the End User Agreement:

www.umlib.nl/taverne-license

Take down policy

If you believe that this document breaches copyright please contact us at:

repository@maastrichtuniversity.nl

providing details and we will investigate your claim.
}

Copyright and moral rights for the publications made accessible in the public portal are retained by the authors and/or other copyright owners and it is a condition of accessing publications that users recognise and abide by the legal requirements associated with these

- Users may download and print one copy of any publication from the public portal for the purpose of private study or research.

- You may not further distribute the material or use it for any profit-making activity or commercial gain

If the publication is distributed under the terms of Article $25 \mathrm{fa}$ of the Dutch Copyright Act, indicated by the "Taverne" license above, 


\title{
Don’ t you Dare Look at me, or else: Negative and Aggressive Interpretation Bias, Callous Unemotional Traits and Type of Aggression
}

\section{Cima $\mathbf{M}^{1,2^{*}}$, Vancleef $\mathbf{L} \mathbf{M ~ G}^{3}$, Lobbestael $\mathbf{J}^{3}$, Cor Meesters ${ }^{3}$ and Korebrits $\mathbf{A}^{4-6}$}

${ }^{1}$ Department Developmental and Forensic Psychology, Tilburg University, The Netherlands

${ }^{2}$ Forensic Psychiatric Center, De Rooyse Wissel, Venray, The Netherlands

${ }^{3}$ Department of Clinical Psychological Science, Faculty of Psychology and Neuropsychology, Maastricht University, The Netherlands

${ }^{4}$ School of Mental Health and Neuroscience, Maastricht University, The Netherlands

${ }^{5}$ St. Joseph Foundation, Juvenile Delinquency Facility, Het Keerpunt, Cadier en Keer, The Netherlands

${ }^{6}$ Mondriaan Mental Health, Child and Adolescent Psychiatry, Heerlen, The Netherland

${ }^{*}$ Corresponding author: Maaike Cima, Department of Developmental and Forensic Psychology, Tilburg University, P.O. Box 90153,5000 LE Tilburg, Netherlands, Tel: 311-3 466- 4101; E-mail: M.J.Cima@uvt.nl

Received date: January 2, 2014, Accepted date: March 28, 2014, Published date: April 4, 2014

Copyright: ( 2014 Cima M, et al. This is an open-access article distributed under the terms of the Creative Commons Attribution License, which permits unrestricted use, distribution, and reproduction in any medium, provided the original author and source are credited.

\begin{abstract}
The aim of the present study was to examine whether there is a relation between a negative/aggressive interpretation bias, different types of aggression, and callous-unemotional traits in (delinquent) juveniles. We examined this research question in 2 different studies. The first study examines the relationship between a social negative interpretation bias with different types of aggression and callous-unemotional traits in 42 juvenile delinquent boys from a Juridical Youth Institution Centre and 29 healthy juvenile controls from a local high school in the Netherlands. Results showed that a negative interpretation bias was related to callous-unemotional traits, but specifically within the delinquent group. In the second study we examined this research question in more detail, using 3 different groups and two different measurements of a negative and aggressive interpretation bias (i.e., explicit vs. implicit measurement, respectively). This second study included 88 male participants ranging from 13 to 25 years. Subjects were now recruited from a local high school (healthy controls), an education project (at risk group) and from a Juridical Youth Institution (juvenile group). In the three different groups, there emerged different meaningful correlates. While in the healthy control group there were no significant correlates of a negative interpretation bias, for the two other groups some meaningful correlates were found. Within the at risk group, an aggressive interpretation bias was related to reactive aggression. Within the delinquent group, a negative interpretation bias was significantly related to reactive aggression, while an aggressive interpretation bias was significantly related to proactive aggression. So over the two studies, specifically within the delinquent groups, a negative interpretation bias seems positively related to aggression and callous-unemotional traits. These findings might indicate that the tendency to make negative or aggressive interpretations of potential innocuous situations might form an important mechanism underlying the relation between aggressive acts and the presence of elevated aggression and callous unemotional traits.
\end{abstract}

\section{Study 1}

\section{Introduction}

According to the social information-processing model of Crick and Dodge [1-3], aggressive behaviour arises from a tendency to interpret other people's intentions as hostile and aggressive. This tendency is also present in ambiguous, non-provoking or threatening situations, were others' intentions are benign [4-6]. This tendency is labelled as Hostile Attribution Bias and relates to incorrect interpretation within social situations, which is step 2 of the social information processing model of Crick and Dodge [1]. Step 1 of this model includes Coding information and step 2 includes the interpretation of cues from the environment. Step 3 comprises of goal clarification, followed by step 4, generating different response possibilities. Step 5 involves evaluating and selecting certain response possibilities followed by the last step, translating the selected response to behavioural actions [2]. These steps are not so much a conscious process, but appear on an unconscious level $[2,7]$.

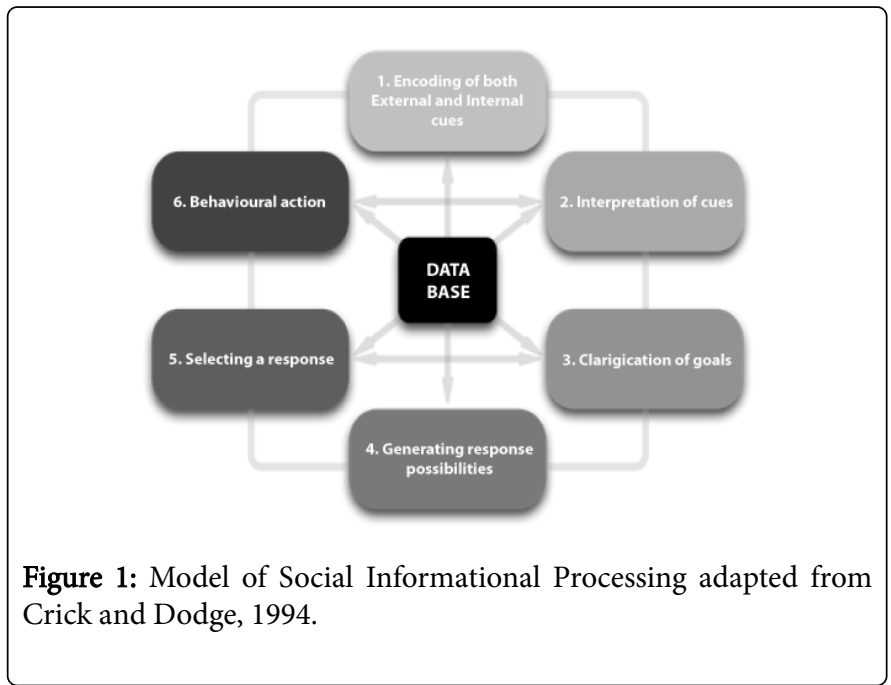


In a study by [8], there was a significant relationship between a hostile attribution bias and aggressive behaviour. One subdivision of aggression often reported in the literature, is between proactive and reactive aggression $[1,9,10]$. Reactive aggression is characterized by impulsivity and aggression in reactions to real or imaginary threat, provocation, or frustration [1]. This is the type of aggression, which according to the frustration-aggression model of Berkowitz [11], is explained by an inner frustration leading to aggression and hostility. In contrast, proactive aggression constitutes instrumental, predatory characteristics and is not a response to provocation but a way to reach a certain goal $[1,9]$. Individuals characterized by this type of aggression expect their behaviour to lead to positive advances and are not engaged in possible negative consequences of their behaviour for others [3]. During different steps of the social information-processing model certain biases are expected to cause different types of aggression. Research has demonstrated that incorrect encoding and incorrect interpretation (step 1 and 2) relate to reactive aggression $[1,3,12,13]$, while proactive aggression relates more to the formulation of atypical interaction goals (Step 3) [14], generating aggressive strategies (step 4) [12], generating a limited diversity of strategies (Step 5) [15], and a positive evaluation of using aggressive behaviour (Step 6) [16]. Research in children has shown that reactive aggression relates positively to a hostile interpretation bias, while proactive aggression relates negatively with a hostile interpretation bias $[1,13,17]$. Furthermore, several studies reported that proactive aggression, but not reactive aggression, relates to psychopathic traits $[9,18,19]$. This is a corresponding finding with a study by [20] demonstrating that children with psychopathic traits show more proactive aggression [21]. An important dimension of psychopathy is the presence of callous, unemotional characteristics, so called Callous-Unemotional (CU)traits. Individuals characterized by these traits are cold, callous, and lack moral emotions like regret, shame, and remorse [22]. Studies regarding the relationship between these $\mathrm{CU}$-traits and negative interpretation bias are sparse. One study reported CU-traits to have an unique and strong association with aggressive responses [23]. The first study is a first and modest step to examine the relationship between negative interpretation bias, types of aggression (reactive versus proactive), and CU-traits in (delinquent) juvenile boys.

\section{Method}

\section{Participants}

The total sample consisted of 57 Dutch adolescent boys who ranged in age from 13 to 20 years $(M=15.46, S D=1.53)$. The first group $(n=28)$, consisting of delinquent juveniles had a mean age of 15.93 $(\mathrm{SD}=1.76)$ years, and were recruited from the Juridical Youth Institution Stichting Jeugdzorg Sint Joseph, located in Cadier en Keer, the Netherlands. Participation was voluntary with random sampling. If participants were not meeting the exclusion criteria, and had a conviction for committing one or more crimes, they were included for the study. Response rate was about $35 \%$. Since this group included only boys, within the control group, only boys were included too. Boys with a criminal history were excluded from the second group. The second group $(n=29)$ consisted of healthy control juveniles from a local high school (Stella Maris high school, also located in the south of the Netherlands), and had a mean age of $14.66(\mathrm{SD}=1.04)$ years. This school was selected because they are situated near to the Juridical Youth Institution. Exclusion criteria for both groups included severe difficulties in understanding the Dutch language or severe psychiatric impairment (substance abuse or an acute psychosis). Participants were also excluded if written and informed consent from both the juvenile and one of the parents or legal guardian could not be obtained. The educational level of the delinquent and control group was highly comparable. However, the delinquent juveniles were slightly, but significantly older than the control group $[\mathrm{t}(55)=3.33$; $\mathrm{p}<.05]$. Since analyses controlling for age did not lead to different results, age is not controlled for in further analyses.

\section{Measures}

\section{The negative interpretation questionnaire}

The Negative Interpretation Questionnaire (NIQ) is an explicit measure to examine interpretations within ambiguous social situations [24], modified this questionnaire, based on the interpretation questionnaire developed by [25]. The original version of the NIQ was in English. For the present study a Dutch translation was used. Since the original NIQ was used for an adult population some of the items of the original NIQ were adjusted in order to make the questionnaire suitable for juveniles with approval of the author of the original NIQ. The NIQ has proven in earlier research to be a reliable and valid instrument with a good internal consistency (alpha $=0.88$ ), [24]. In the current study the internal consistency was also adequate (alpha $=0.77$ ). The NIQ consists of 22 scenarios, which can be divided into direct social interactions (15 items), for example, "You walk on the street and you pass a group of people talking. They start laughing when you pass them," or not involving a direct social interaction (7 items) "You come home and find a note in your mailbox." In each scenario, participants are provided with three alternative interpretations of that particular scenario. There is a positive interpretation ("They like the way you are dressed."), a negative interpretation ("They are making fun of you.") and a neutral interpretation ("One of them just told a joke"). Subjects were asked to rate the three alternative interpretations in the order that they are most likely to come to mind. The most likely interpretation was rated with " 1 ", the second most likely interpretation was rated with " 2 ", and the least likely interpretation was rated with " 3 ". Only scores on the negative interpretations are summed in order to achieve a Total Score. Scores can range between 22 and 66. Therefore, the lower the score on this questionnaire, the higher the negative interpretation bias.

\section{Reactive-proactive aggression questionnaire}

Adrian Raine [26] originally developed The Reactive Proactive Questionnaire (RPQ), which measures two important types of aggression; reactive, impulsive aggression and proactive, instrumental aggression. For the present study, we used the Dutch translation of the RPQ [27]. The RPQ can be applied to anyone with the reading level of an 8-year-old child. The questionnaire consists of 23 items, of which 12 items are proactive (e.g., "How often did you have fights to show who was on top") and 11 items are reactive (e.g., "How often have you damaged things because you felt angry"). The items of the RPQ reflect either physical or verbal aggression and include the motivation and situational context for the aggression. Answers are given on a 3-point scale where $0=$ never, $1=$ sometimes and $2=$ often. Scores are calculated on a proactive, a reactive and a total scale. The total scale consists of the summed total of the proactive and reactive subscales. The total score can range from 0 to 46 . The RPQ has proven in earlier research to be a reliable and valid instrument $[26,27]$. The RPQ also had good internal consistency (alpha $=0.85$ ). In the current study the internal consistency has also proven to be good (alpha $=0.87$ ). 


\section{Inventory of callous-unemotional traits}

In order to have a reliable and valid assessment to measure Callous Unemotional Traits, [28] developed a self-report measure called the Inventory of Callous-Unemotional Traits (ICU). The ICU consists of 24 items that can be divided into 3 different subscales. Research showed that three factors underlie the ICU, which relate to a higherorder callous-unemotional dimension. These include Callousness (e.g., "I do not care about doing things well"), Unemotional (e.g., "I express my feelings openly"; reversed coded) and Uncaring (e.g., "I work hard on everything I do" (reversed coded)) traits. As assessed by the ICU, $\mathrm{CU}$ traits were associated with aggression, delinquency and both psycho physiological and self-report indices of emotional reactivity $[22,28]$. All of the items on the ICU can be scored on a 4-point scale where $0=$ not at all true, $1=$ sometimes true, $2=$ almost true and $3=$ absolutely true. Scores can be most reliable interpreted on the total score [29]. The total score ranges between 0 to 72 , in which the higher the score, the more CU traits present. The ICU has proven in earlier research to be a reliable and valid instrument with good internal consistency (alpha=0.86), [28,29]. In the current study the Dutch translation of the ICU [30] was used. Internal consistency in the present sample has proven to be good (alpha $=0.77)$.

\section{Procedure}

The study was approved by the Ethical Committee Psychology of Maastricht University. All 57 participants where personally asked by the researcher if they wanted to participate in this study. After informed consent was obtained from the participant as well as the parent(s) or legal guardian, each eligible participant was asked to fill out the 3 questionnaires and some general questions (age, education). Questionnaires were counterbalanced in order to minimize an ordereffect.

Within the delinquent group, participants were tested individually in one session of about 30 minutes. The questionnaires were administered in a quiet room with only chairs, a table and paper and pencil tests. They filled in the questionnaires under the supervision of the researcher who was available for questions or explanation during the session. Within the healthy controls group, participants were asked to fill out the questionnaires in small groups of 3 participants during a 30 minute session in an empty classroom under the supervision of the researcher. After completing the questionnaires, participants received a chocolate bar as a reward for their efforts.

\section{Statistical Analyses}

First, normality of the variables was examined using Skewness and Kurtosis. All variables were in the normal range between 1 and -1 . Secondly, in order to compare the groups on the Negative Interpretation Bias (NIB), Type of Aggression and CallousUnemotional Traits (CU-traits), independent T-tests were performed. Thirdly, to be able to examine the relationship between the variables, a correlational analysis was performed between NIB, Type of aggression, and CU-traits. This was done for the total sample. Additionally, since we were mainly interested in relationships of a NIB with specific characteristics (callousness and aggression), and whether this relationship would be different within the groups (delinquents and healthy controls), correlational analysis was performed for the groups separately ${ }^{1}$. In case of significance, Cohen's d is reported. All statistical analyses were performed using SPSS version 21 (e.g., IBM, 2012).

\section{Results}

As to the Total Score on the NIB, results showed that the delinquent group had significant higher score, indicating that the control group had more negative interpretation bias $[\mathrm{t}(55)=3.21 ; \mathrm{p}<.001 ; \mathrm{d}=.82]$. However, this difference was found to be specific for situations describing direct social interactions $[\mathrm{t}(55)=3.73 ; \mathrm{p}<.001 ; \mathrm{d}=.81]$, whereas there were no group differences on the items not involving a social interaction $[\mathrm{t}(55)=.93 ; \mathrm{p}=.36]$.

As to the types of aggression, delinquents demonstrated both significantly higher reactive $[\mathrm{t}(55)=2.28 ; \mathrm{p}<.05 ; \mathrm{d}=.60]$ as well as proactive aggression scores $[\mathrm{t}(55)=2.43 ; \mathrm{p}<.05 ; \mathrm{d}=.53$ ]. On the ICU, there were no significant group differences $[\mathrm{t}(55)=.29 ; \mathrm{p}=.77]$; see Table 1 for the means and SD's.

\begin{tabular}{|l|l|l|l|l|}
\hline & NIB & RA & PA & CU-traits \\
\hline Controls & 41.76 & 7.93 & 3.34 & 27.9 \\
\hline & -5.38 & -3.29 & -2.77 & -8.64 \\
\hline
\end{tabular}

Table 1: Means and SD's on the Negative Interpretation Bias (NIB), Reactive Aggression (RA), Proactive Aggression (PA), and Callous Unemotional traits (CU-traits; $\mathrm{N}=57$ ).

To examine the relationship between a NIB, Type of Aggression and CU-traits, a correlational analysis was performed. For the total group, there was a significant correlation between a NIB and CU-traits $[\mathrm{r}=-.39 ; \mathrm{p}<.01]$. Types of aggression were not significantly related to a NIB [all r's > -.09; all p's > .36]. To investigate whether these relationships were different for the two groups, correlational analysis was done separately. See Table 2 for the results.

\begin{tabular}{|l|l|l|l|l|}
\hline & & RA & PA & CU-traits \\
\hline \multirow{3}{*}{ Controls } & NIB & -.10 & -.06 & -.19 \\
\cline { 2 - 5 } & RA & - & $.65^{* *}$ & .25 \\
\cline { 2 - 5 } & PA & $.65^{* *}$ & - & $.41^{*}$ \\
\hline \multirow{3}{*}{ Delinquents } & NIB & -.31 & $-.39^{*}$ & $-.60^{* *}$ \\
\cline { 2 - 5 } & RA & - & $.54^{* *}$ & .06 \\
\cline { 2 - 5 } & PA & $.54^{* *}$ & - & .26 \\
\hline \multirow{2}{*}{ Note: ${ }^{*}: p<.05 ; *: p<.01$} & & & \\
\hline
\end{tabular}

Table 2: Correlational analysis between Negative Interpretation Bias (NIB), Reactive Aggression (RA), Proactive Aggression (PA), and Callous Unemotional traits (CU-traits) for the control group $(\mathrm{n}=29)$ and delinquent group $(\mathrm{n}=28)$ separately.

1 Although it would also be interesting to examine predictors of a NIB within the total sample, the main goal of the current study was to examine relations between NIB and certain characteristics. Moreover, while comparing the predictive value of e.g. both aggression types and personality characteristics could have the advantage to be able to draw specific conclusions, some authors have cautioned against such an approach because of the difficulty of understanding what these unique variables represent [31]. 
As can be seen from Table 2, proactive aggression and CU-traits were both significantly related to a NIB, but only within the delinquent group. In the control group, a NIB was not significantly related to either types of aggression, nor CU-traits. To examine whether this pattern was also found when splitting the items of the NIB into those involving social versus not social interactions, a correlational analysis was performed for these set of items separately. As can be seen from Table 3, CU-traits were still significantly correlated with both types of ambiguous situations, while proactive aggression was only significantly related to ambiguous situations not involving a social interaction.

\begin{tabular}{|l|l|l|l|l|}
\hline & & RA & PA & CU-traits \\
\hline \multirow{3}{*}{ Controls } & Social & -.18 & -.18 & -.14 \\
\cline { 2 - 5 } & Not social & .08 & -.18 & -.15 \\
\hline \multirow{2}{*}{ Delinquents } & Social & -.28 & -.33 & $-.57^{\star *}$ \\
\cline { 2 - 5 } & Not social & -.28 & $-.40^{*}$ & $-.51^{\star *}$ \\
\hline
\end{tabular}

Note: ${ }^{*}: p<.05 ;{ }^{* *}: p<.01$

Table 3: Correlational analysis between Negative Interpretation Bias (NIB) items involving social and not social interactions, Reactive Aggression (RA), Proactive Aggression (PA), and Callous Unemotional traits (CU-traits) for the control group $(\mathrm{n}=29)$ and delinquent group $(n=28)$ separately.

To examine whether the combination of being a delinquent and having high CU-traits is more related to a NIB than being a delinquent with low CU-traits, median split of the ICU was used to split the groups in high versus low CU traits. As can be seen from figure 2, within the control group, having high or low CU-traits does not influence their NIB. However, the CU traits seemed especially important in the combination with delinquency. So although controls show lower NIB scores (indicating a higher NIB), it is especially the combination of being a delinquent and having high CU-traits, which relates to a higher NIB, while the controls showed the same NIB regardless of their $\mathrm{CU}$-traits.

This is supported by the independent t-test, showing that there was no significant difference between healthy controls with and without CU-traits regarding their NIB [ $\mathrm{t}(27)=.40 ; \mathrm{p}=.69$ ], while delinquents with CU traits showed significant lower NIB scores (a higher NIB) as compared to delinquents without $\mathrm{CU}$ traits $[\mathrm{t}(26)=3.45 ; \mathrm{p}<.05]$. There were no significant group differences regarding NIB when looking at high versus low reactive and proactive aggression [all t's 1.39; all p's $>$. 17].

Figure 2: NIB for Delinquents and Healthy Controls varying in their levels of CU-traits.

\section{Conclusion}

In general, for all participants, it can be concluded that the presence of callous, indifference, unemotional personality traits, make individuals vulnerable to interpret the world as a hostile place (they do not like me; people are against me). Although CU-traits do not significantly differ between the juvenile delinquent and control group, only within the juvenile delinquent group, these $\mathrm{CU}$-traits were significantly related to a NIB, while this was not the case within the healthy controls sample. Consequently, CU traits seemed especially relevant in combination with delinquency regarding the interpretation of ambiguous situations as negative. However, also healthy controls high on CU-traits demonstrated high NIB. One explanation for the finding of higher NIB in healthy controls as compared to delinquents could be that during puberty, adolescents in general may be vulnerable to social evaluations. Indeed, the higher NIB in the healthy control group, was specifically for ambiguous situations describing social interactions. However, this NIB was not found to be related to types of aggression or CU-traits within the healthy controls.

Another explanation for the finding of similar bias in both groups might be that the explicit measure (self-report questionnaire format) left room for social desirable answers, especially within the delinquent sample [32]. Therefore, in the follow-up study, besides the measurement of the NIB, an implicit instrument was administered measuring an aggressive interpretation bias.

\section{Study 2}

\section{Introduction}

In the former study, especially high CU-traits in combination with delinquency predicted a tendency to interpret information negatively. Neither reactive nor proactive aggression was related to a negative interpretation bias. The above mentioned study used only one measure of negative interpretation bias. This measure was an explicit instrument in which participants were asked to indicate how they would interpret certain situations. In order to measure an interpretation bias less obviously, an implicit measure of an aggressive interpretation bias may be more informative. Former studies using such an implicit measure of an interpretation bias have been performed within anxiety research [33]. However, studies using an implicit measure of aggression within juvenile participants varying in their levels of delinquency have not been performed yet. Therefore, the present study examines not only a negative but also an aggressive interpretation bias using both an explicit as well as an implicit instrument in a healthy control, an at risk group, and a delinquent group of juveniles. Again, as with study 1, we were mainly interested in the relationship of these NIB and AIB within different groups.

\section{Method}

\section{Participants}

The second study included 88 male participants ranging from 13 to 25 years. The subjects were recruited at 3 different sites. First, 20 adolescents were enrolled from a high school in the surrounding area of Maastricht, the Netherlands, who had never spent any time in a juvenile correctional institution. This sample was selected because the schools were situated in the South of the Netherlands, were the study was conducted, and was the healthy control sample with a mean age of 14 years (ranging from 12 to $17, \mathrm{SD}=1.47$ ). The researcher presented the study before the classroom after which participants could indicate whether they were willing to participate in the current study. Sampling was random and it was emphasized that participation was voluntary. Secondly, 19 young adults were recruited from several educational projects in Eindhoven, the Netherlands. These educational projects are created for adolescents and young adults who dropped out of high school, thereby not able to finish school and have also not pursued any 
further education. Since they have no education, these individuals are often unable to find employment and to build a successful career. The reasons they dropped out of school, often have to do with borderline criminal behavior (such as vandalism). Because of their behavior, these individuals were not able to function in a normal way at high school. However, these subjects have never spent any time in a juvenile or adult correctional institution. The educational projects therefore include training, schooling and supervision for future internships. Again, the researcher introduced the study in front of a class after which individuals could sign up for participation. Sampling was random, as long as participants did not meet the exclusion criteria. Since these individuals do show problem behavior, this group was labeled the at risk group, with a mean age of 20 years (ranging from 17 to $25, \mathrm{SD}=2.29$ ). Thirdly, 49 adolescents were enrolled from a Juridical Youth Institution called Stichting Jeugdzorg Sint Joseph, located in Cadier en Keer, the Netherlands. The researcher explained the study to groups of 8 juveniles after which they could indicate whether they were willing to participate. Sampling was random and voluntary. Individuals from this group have all committed a criminal offence and are therefore labeled the delinquent group, with a mean age of 16 years (ranging from 13 to $21, \mathrm{SD}=1.71$ ).

The three research groups differed significantly in age $[F$ $(4,162)=15.95, \mathrm{p}<.01]$. However, controlling for age in further analyses did not influence the results. Therefore, age was not controlled for in all subsequent analyses.

\section{Measures}

\section{The negative interpretation questionnaire}

This questionnaire is the same instrument as used in the first study and is used to assess if subjects have the tendency to negatively interpret ambiguous social situations (see study 1). Some items were not relevant for youth samples, and therefore, in this second study, these 3 items were excluded from the NIB resulting in a questionnaire of 19 items. The Negative Interpretation Questionnaire is an explicit measure to test the negative interpretation bias in social and non-social contexts.

\section{Aggressive Interpretation Task}

The Aggressive Interpretation-task was designed to measure a possible interpretation bias towards aggression. The interpretation bias is assessed with an ambiguous homograph priming task, which was first used in prior studies aiming to assess anxiety-related interpretations [34], but was later modified for the purpose of the present study. In this task, participants have to decide whether a string of letters is either an existing or a non-existing Dutch word (nonword). Before a subject has to decide whether the string of letters is a word or a nonword, the subjects are primed with an ambiguous word (e.g., beat). Then, $750 \mathrm{~ms}$ after the presentation of the prime word, a word from one of three conditions follows the prime. The word "beat" can be followed by "exceed" or "music" (not relevant because it is not aggressively related, but it is semantically related), it can be followed by "chair" (not relevant and not semantically related), or it can be followed by "hit" (both relevant and semantically related). The word "beat" can also be followed by a nonword (e.g., frbuk) in the control condition. Now it is all about how fast a participant makes the decision whether the letter string that is presented (music, chair, hit or frbuk), is a real word or a nonword. Both the accuracy of these lexical decisions as well as the reaction times are recorded. The theory behind this task is that a person with an aggressive bias will make the decision regarding a word vs nonword faster if the word includes a relevant as well as semantically related content (i.e., "hit") as compared to the decision about the words "chair" or "music". Interpretation bias is derived from the difference score of reaction times to not aggression relevant and aggression relevant semantically related words following ambiguous aggression primes. Positive difference scores are then indicative of aggressive interpretation bias.

The task consists out of 84 trials. This means that 84 prime-target word pairs are shown, containing a total of 168 words. There are 21 critical trials included in the task, which were selected from a previous pilot study ${ }^{2}$. These 21 critical trials were subdivided into seven critical trials in each condition, with exception to the control condition. The critical word pairs were distributed over three different word lists. These three lists led to three conditions of the task. All three conditions contained the same 21 critical ambiguous prime words, but the target words that followed the primes were counterbalanced over the three conditions. This led to each task condition consisting of seven relevantrelated prime target pairs, seven not relevant-related prime target pairs and seven unrelated prime target pairs (e.g., the prime "beat" was followed by the relevant-related target "hit" for one-third of all participants, by the not relevant-related target "music" by one-third of participants and by the word "chair" by the final third of participants).

Next, neutral filler tasks were incorporated in the task to make sure that the actual goal of the task was not transparent to the participants. Subjects had to be under the impression that they are completing a lexical decision task, not that they are being assessed for their reactions to aggression-related ambiguity. To make sure that equal proportions of unrelated and related targets in the task are preserved, seven ambiguous words with a neutral related word and 14 ambiguous primes with unrelated target words were added.

The Aggressive Interpretation task is an implicit task to measure a possible aggressive interpretation bias (AIB), since participants are not aware of what is being measured. Thus, to maintain the idea that the subjects are completing a lexical decision task, 42 prime target pairs were added to the task, in which the prime was an ambiguous neutral word and the target was a nonword. This way, the proportion of nonwords is kept equal to the proportion of real words. Subjects were instructed to respond as quickly and accurately as possible. If the participant decided that the stimulus was a real word, he was asked to push "P" on the computer keyboard with his right hand. If he decided that it was not a real word, he had to push "Q" with his left hand. The participants were first given a practice session to help them get a better understanding of the task. After the practice session, the actual experiment began.

\section{Reactive-proactive aggression questionnaire}

The Reactive-Proactive Aggressive Questionnaire (Raine et. al., 2006) was used to assess reactive and proactive aggression [27].

245 Ambiguous words were rated by 43 participants. Only those words with an aggressive rating above $80 \%$ were included in this task, leaving 21 words useful for this task. 


\section{Psychopathic personality inventory}

The Psychopathic Personality Inventory (PPI), [35], is a self-report questionnaire to measure psychopathic traits. The PPI consists of 187 items which are divided into eight subscales. The eight subscales are: Machiavellian Egocentricity (30 items), Social Potency (24 items), Coldheartedness (21 items), Carefree Nonplanfulness (20 items), Fearlessness (19 items), Blame Externalization (18 items), Impulsive Nonconformity (17 items), and Stress Immunity (11 items). The questionnaire includes a 4 -point scale $(1=$ false, $2=$ mostly false, $3=$ mostly true, and $4=$ true), with a maximum total score of 652 and a minimal Total score of 163 . Twenty four items are not included in the total score. The internal consistency of the PPI is good, with Cronbach's alphas ranging from 0.90 to $0.93[35,36]$. The Dutch version of the PPI was used [37].

\section{Procedure}

The study was approved by the Ethical Committee Psychology of Maastricht University as well as by the scientific committee of the Juridical Youth Center (Stichting Jeugdzorg Sint Joseph).

All participants were verbally and by means of written instructions, informed about the study. When the subjects agreed to participate in the study, they were asked to sign an informed consent. In case the individual was younger than 18 years, their parents or legal guardian were addressed to sign an informed consent as well. Individuals were explained that participation in the present study was voluntary and anonymous and that they were allowed to stop at any time during the study, without having to explain why they chose to stop. All participants were compensated for participation.

The general procedure for the three different groups was the same, in which the information was given to the participants and they signed the informed consent, some biographical information was asked at the beginning of every trial. This biographical data included age, (possible) criminal history, and level of education. Next, computer tasks or questionnaires were administered. Computer tasks and questionnaires were counterbalanced. Participants were also administered a selective attention task (Dot Probe), but since results of this task were not interpretable, these data are not included in the ms. Participants were tested individually in a room which consisted only of a table, chairs and a laptop. Participants completed all tests within approximately 60 minutes.

\section{Statistical analyses}

For the computer task, only correct responses to word trials were considered in analyses. To examine differences between the three groups regarding types of aggression, psychopathic traits, and interpretation biases, One Way ANOVA's with follow-up T-tests were performed. In order to investigate the relationship between types of aggression, psychopathic traits, and interpretation biases, correlational analyses for separate groups were performed. In case of significance, Cohen'd is reported. All statistical analyses were performed using SPSS version 21 (e.g., IBI, 2012).

\section{Results}

Overall results showed that there were significant differences between the three groups regarding reactive aggression $[\mathrm{F}(2,76)=5.35$; $\mathrm{p}<.01]$, proactive aggression $[\mathrm{F}(2,76)=12.06 ; \mathrm{p}<.001]$, and psychopathic characteristics $[\mathrm{F}(2,76)=163.92 ; \mathrm{p}<0.01]$. Post Hoc comparisons showed that the difference in reactive aggression was due to the delinquent group having higher scores than the healthy controls $[\mathrm{t}(58)=3.33 ; \mathrm{p}<.001 ; \mathrm{d}=.87]$. There were no significant differences between the at risk group and the delinquent group $[p=.28]$, or between the at risk group and the healthy controls [p=.07]. Regarding proactive aggression, differences were due to the high scores of the delinquent group versus the at risk group $[\mathrm{t}(57)=1.10 ; \mathrm{p}<.05 ; \mathrm{d}=.29]$, the delinquent group versus the healthy controls $[\mathrm{t}(58)=4.85 ; \mathrm{p}<.001$; $\mathrm{d}=1.27]$, and the at risk group scoring higher than the healthy controls $[\mathrm{t}(37)=1.85) ; \mathrm{p}<.05 ; \mathrm{d}=.61]$. For the psychopathic traits, significant group differences were due to the at risk group scoring significantly higher than the delinquent group $[\mathrm{t}(66)=16.49 ; \mathrm{p}<.001 ; \mathrm{d}=4.06]$, and the healthy controls $[\mathrm{t}(37)=14.07 ; \mathrm{p}<.001 ; \mathrm{d}=4.63]$. There were no significant differences between the delinquent group and the healthy controls $[\mathrm{t}(67)=.35 ; \mathrm{p}=.73]$. Regarding the Interpretation Biases, group differences were also significant $[\mathrm{F}(2,80)=5.99 ; \mathrm{p}<.01]$ for the Negative Interpretation Bias (NIB), but not for the Aggression Interpretation Bias (AIB) $[\mathrm{F}(2,80)=2.05 ; \mathrm{p}=.14]$. Differences on the NIB were due to the healthy controls showing more negative interpretation bias as compared to the delinquent group $[\mathrm{t}(66)=3.15 ; \mathrm{p}<.001 ; \mathrm{d}=.78]$. There were no significant differences regarding a NIB between healthy controls and the at risk group $[\mathrm{t}(36)=1.29) ; \mathrm{p}=.21]$, and the at risk group versus the delinquent group $[\mathrm{t}(64)=1.51 ; \mathrm{p}=.14]$. However, for the NIB-items not involving a social interaction, delinquents had less NIB as compared to the at risk group [ $\mathrm{t}(64)=4.73 ; \mathrm{p}=.000 ; \mathrm{d}=1.18]$. No significant differences were found for the NIB-items involving social interaction $[\mathrm{t}(64)=-.19 ; \mathrm{p}=.85]$. Table 4 shows the mean and SD's of the different groups.

\begin{tabular}{|l|l|l|l|l|l|}
\hline & RA & PA & $\begin{array}{l}\text { PP- } \\
\text { traits }\end{array}$ & $\begin{array}{l}\text { Negative } \\
\text { Interpretation } \\
\text { Bias }\end{array}$ & $\begin{array}{l}\text { Aggression } \\
\text { Interpretation } \\
\text { Task }\end{array}$ \\
\hline $\begin{array}{l}\text { Healthy } \\
\text { Controls }\end{array}$ & $\begin{array}{l}8.60 \\
(3.95)\end{array}$ & $\begin{array}{l}2.30 \\
(2.05)\end{array}$ & $\begin{array}{l}229.30 \\
(20.52)\end{array}$ & $\begin{array}{l}42.55 \\
(6.44)\end{array}$ & $\begin{array}{l}32.68 \\
(152.59)\end{array}$ \\
\hline $\begin{array}{l}\text { At Risk } \\
\text { Group }\end{array}$ & $\begin{array}{l}11.16 \\
(4.67)\end{array}$ & $\begin{array}{l}5.00 \\
(4.29)\end{array}$ & $\begin{array}{l}388.68 \\
(46.12)\end{array}$ & $\begin{array}{l}45.17 \\
(6.03)\end{array}$ & $\begin{array}{l}62.42 \\
(122.80)\end{array}$ \\
\hline Delinquents & 12.55 & 7.88 & 230.35 & 48.07 & -10.92 \\
& $(4.50)$ & $(4.91)$ & $(31.19)$ & $(5.93)$ & $(134.98)$ \\
\hline
\end{tabular}

Table 4: Means and SD's of Reactive Aggression (RA), Proactive Aggression (PA), Psychopathic (PP-)-traits, Negative Interpretation Bias and Aggressive Interpretation Bias $(\mathrm{N}=88$; for the RPQ $\mathrm{N}=79)$.

To investigate the relationship between a NIB, AIB, Type of Aggression, and CU-traits, a correlational analysis was performed. For the total group, there were no significant correlations [all r's $<.18$; all p's $>$.10]. To examine whether these relationships were different for the three groups, correlational analysis was done separately. See Table 5 for the results.

\begin{tabular}{|l|l|l|l|l|l|}
\hline \multirow{3}{*}{ Controls } & & NIB & AIB & PA & RA \\
\hline & NIB & - & .05 & -.40 & -.43 \\
\cline { 2 - 7 } & AIB & .05 & - & -.02 & -.29 \\
\cline { 2 - 7 } & PA & -.40 & -.02 & - & -.02 \\
\cline { 2 - 6 } & RA & -.43 & -.29 & -.02 & - \\
\cline { 2 - 6 } & PP-traits & .14 & -.41 & -.41 & .08 \\
\hline
\end{tabular}




\begin{tabular}{|l|l|l|l|l|l|}
\hline \multirow{4}{*}{ At Risk } & NIB & - & -.23 & -.11 & -.38 \\
\cline { 2 - 6 } & AIB & -.23 & - & .44 & $.56^{*}$ \\
\cline { 2 - 6 } & PA & -.11 & .44 & - & $.81^{* *}$ \\
\cline { 2 - 6 } & RA & -.38 & $.56^{*}$ & $.81^{* *}$ & - \\
\cline { 2 - 6 } Delinquents & PP-traits & -.05 & -.10 & $.49^{*}$ & .34 \\
\hline & NIB & - & -.11 & -.18 & $-.32^{\star}$ \\
\cline { 2 - 6 } & AIB & -.11 & - & $.32^{*}$ & .27 \\
\cline { 2 - 6 } & PA & -.18 & $.32^{*}$ & - & $.32^{*}$ \\
\cline { 2 - 6 } & RA & $-.32^{\star}$ & .27 & $.32^{\star}$ & - \\
\cline { 2 - 6 } & PP-traits & $-.37^{*}$ & .25 & $.64^{* *}$ & $.60^{* *}$ \\
\hline
\end{tabular}

Note: ${ }^{*}: p<.05 ;{ }^{* *}: p<.01$

Table 5: Correlational analysis separated by group between Reactive Aggression (RA), Proactive Aggression (PA), Psychopathic-traits (PPtraits), Negative Interpretation Bias (NIB), and Aggressive Interpretation Bias (AIB)

The correlational analysis for the three groups showed that within the healthy controls, there were again no significant correlates of a negative and an aggressive interpretation bias. Furthermore, within the at risk group an aggressive interpretation bias was found to be significantly related to reactive aggression. Within the delinquent group a negative interpretation bias was significantly related to reactive aggression, while an aggressive interpretation bias was significantly related to proactive aggression (Table 5).

\section{Conclusion}

The AIB was differentially related to type of aggression depending on group. In other words, for the at risk group the AIB was related to reactive aggression, while for the delinquent group the AIB was related to proactive aggression. So being a reactive non-criminal juvenile, or being a delinquent juvenile with proactive aggressive traits is associated with an aggressive interpretation bias of verbal ambiguous stimuli. Furthermore, the explicit interpretation bias regarding negative situations (NIB) was related to reactive aggression within the delinquent group. So types of aggression are differentially related to a NIB and an AIB within the delinquent sample. No relationship with either, negative, nor aggressive interpretation bias emerged within the healthy control group.

\section{General Discussion}

The present study examined Negative and Aggressive Interpretation Bias in healthy, at-risk and delinquent juvenile samples varying in their level of callous unemotional or psychopathic traits.

Based on the Social Information Model of [1], it was expected that a negative interpretation bias would mostly be related to reactive aggression. In the first study, results show that a negative interpretation bias was related to delinquency in combination with CallousUnemotional traits. Although this finding contradicts with what one would expect based on the relationship with reactive aggression and inaccurate coding and interpretation of social information [1,13,17], it actually makes sense that especially delinquents high on Callous
Unemotional traits tend to view the world as a hostile, negative place. For instance, prior research has demonstrated that children with a combination of externalizing problems and high levels of these CUtraits seem to show a more severe, stable, and aggressive pattern of behavior than other youths with externalizing disorders [38]. More importantly, children with externalizing disorders with and without CU traits show very different patterns of emotional processing [39]. Specifically, those children and adolescents with externalizing disorders who are also high on CU traits show problems recognizing negative emotions and show blunted responses to negative emotional stimuli $[20,40-43]$. Therefore, the finding that a NIB was related to a combination of delinquency and CU traits is in line with their failure of correctly recognizing emotional social information.

In line with the results of the first study, the second study also found a relationship between a NIB and psychopathic traits in delinquent juveniles. This relationship was especially true for explicit social information (NIB) and not for implicit aggressive verbal information (AIB). It seems that juvenile delinquents high on callous unemotional psychopathic traits, tend to negatively interpreted ambiguous social information. Along this line of results, research has demonstrated that juvenile delinquents high on psychopathic traits use cognitive distortions like blaming others [44]. In their view, others are hostile, against them, making their lives miserable, and are therefore to blame for their aggressive acts. Psychopathic juvenile delinquents do have moral knowledge of right and wrong [45], but tend to interpret social information negatively, and may consequently use cognitive distortions to ease their conscience [45]. Consequently, juvenile delinquents high on callous psychopathic traits, fail to recognize other persons' intentions adequately, therefore behaving antisocial themselves [1] despite their knowledge of moral rules and values [45]. Interestingly, the AIB was related to both types of aggression within the risk and delinquent group. More specifically, within the delinquent sample, an AIB was related to proactive aggression while this AIB within the risk group was associated with reactive aggression. So depending of the severity of delinquency, an AIB related differentially to these two types of aggression. An interpretation bias for aggression within less severe delinquency (at risk group) related as expected according to the theory of [1], to reactive aggression. In contrast, this bias related to instrumental, proactive, predatory aggression, a type of aggression relating more to psychopathic characteristics [9], in the more severe delinquent group. Perhaps this finding may be due to the outcomes of the delinquent group scoring significantly higher on proactive aggression, while they were equally reactive aggressive as compared to the at risk group. Within the delinquent group, proactive aggression was more related to an aggression bias, while reactive aggression related more to a tendency to interpret social ambiguous situations as negative. Earlier studies have demonstrated that especially proactive aggression relates to psychopathology [46-48]. Therefore the delinquent group may constitute a more psychiatric group of delinquents in which proactive aggression is especially related to an aggressive interpretation bias. Future research might explore the relationship between reactive aggression and an AIB in juvenile delinquents, before and after an anger provocation to examine more precisely the contribution of different types of aggression (reactive versus proactive) in relation to an aggressive interpretation bias.

The current findings may have some implications for clinical practice. Some aggressive juveniles view the world as hostile and negative, in which others are against them, accordingly act aggressive themselves [1]. It seems important to teach these individuals to interpreted certain situations differently. For instance, interventions 
focusing on changing these cognitive distortions may be more effective then to teach these individuals the differences between good and bad. Indeed, several studies showed a discrepancy between cognition (knowing the difference between right and wrong) and behavior (nevertheless behaving aggressively, e.g., [49,50]. In order to recognize and internalize consequences of one's behaviour, one must first restore self-esteem and self-worth [51]. Treatment should therefore focus on restoring self-esteem to improve behavioural evaluation eventually leading to more adequate interpretations of one's surroundings.

The current results have to be seen in light of some limitations. First, groups were relatively small and therefore one must beware of generalization of the results. In line with this, the survey of the current study was quite long, which might have caused low response rate. However, Cohen's d were generally moderate to large, indicating that effect size was good. Secondly, with exception of the computer task, instruments were mainly self-reports. Research has shown that especially within forensic samples, self-report might not be the most reliable method of assessment [32,51]. Therefore, future research regarding negative and aggressive interpretation bias might include more implicit, real life measurements. Thirdly, the reactive aggression scale is part of a self-report questionnaire, which does not evoke emotional responses or cognitions in real life [3]. Future research might focus on more real life provocation methods, for instance using Virtual Reality techniques.

In sum, both current studies report a relationship between NIB with CU-traits (study 1) and Psychopathic-traits (study 2). Previous research demonstrated that callous-unemotional psychopathic delinquents tend to use lower moral reasoning patterns (i.e., cognitive distortions) [45]. The current results add up to that in the sense that a NIB may justify their own behavior (the world is against me, therefore I act aggressively), regardless of the type of aggression being used. Interestingly, healthy controls demonstrated more NIB in both studies, but there were no meaningful personality correlates of a NIB (study1 and 2) and AIB (study 2) within this group. The finding that certain characteristics were related to certain interpretation biases within at risk and delinquent samples, indicate that such biases may be a steering mechanism for aggressive, antisocial behavior. Of course, the current study did not examine causality, and therefore the possibility that the combination of certain personality traits with aggressive behavior may lead to such negative/aggressive interpretation biases cannot be ruled out. However, previous research has already demonstrated that cognitive mechanisms such as an Interpretation Bias, can guide problematic behavior [52]. In line with this assumption, the current results showed that a NIB and AIB seem important mechanisms in especially antisocial individuals (at risk and delinquent samples) in relationship to personality traits and aggressive behavior.

\section{References}

1. Dodge KA, Coie JD (1987) Social-information-processing factors in reactive and proactive aggression in children's peer groups. J Pers Soc Psychol 53: 1146-1158.

2. Crick NR, Dodge K A (1994) A review and reformulation of social information- processing mechanisms in children's social adjustment. Psychological Bulletin, 115: 74-101.

3. de Castro BO, Merk W, Koops W, Veerman JW, Bosch JD (2005) Emotions in social information processing and their relations with reactive and proactive aggression in referred aggressive boys. J Clin Child Adolesc Psychol 34: 105-116.
4. Dodge KA (1980) Social cognition and children's aggressive behavior. Child Dev 51: 162-170.

5. Dodge KA, Frame CL (1982) Social cognitive biases and deficits in aggressive boys. Child Dev 53: 620-635.

6. Dodge KA, Murphy RR, Buchsbaum K (1984) The assessment of intention-cue detection skills in children: implications for developmental psychopathology. Child Dev 55: 163-173.

7. Quiggle NL, Garber J, Panak WF, Dodge KA (1992) Social information processing in aggressive and depressed children. Child Dev 63: 1305-1320.

8. Orobio de Castro B1, Veerman JW, Koops W, Bosch JD, Monshouwer HJ (2002) Hostile attribution of intent and aggressive behavior: a metaanalysis. Child Dev 73: 916-934.

9. Cima M, Raine A (2009) Distinct characteristics of psychopathy relate to different subtypes of aggression. Personality and Individual Differences, 47: 835-840.

10. Dodge KA (1991) The Structure and Function of Reactive and Proactive Aggression. In D.J.Pepler, K H Rubin (Edn.,), The development and treatment of childhood aggression. Toronto, Canada.

11. Berkowitz L (1989) Frustration-aggression hypothesis: examination and reformulation. Psychol Bull 106: 59-73.

12. Brugman S, Lobbestael J, Arntz A, Cima M, Schuhmann T, et al. (Under Revision). Identifying cognitive predictors of reactive and proactive aggression.

13. Crick NR1, Dodge KA (1996) Social information-processing mechanisms in reactive and proactive aggression. Child Dev 67: 993-1002.

14. Slaby RC, Guerra NG (1988) Cognitive mediators of aggression in adolescent offenders: I. Assessment. Developmental Psychology, 24: 580-588.

15. Asarnow JR, Callan JW (1985) Boys with peer adjustment problems: social cognitive processes. J Consult Clin Psychol 53: 80-87.

16. Dodge K A, Schwartz D (1997) Social information processing mechanisms in aggressive behavior. In D M Stoff J, Breiling J D, Maser, (Edn.), Handbook of antisocial behaviour, 171-180. New York: Wiley.

17. Schwartz D, Dodge KA, Coie JD, Hubbard JA, Cillessen AH, et al. (1998) Social-cognitive and behavioral correlates of aggression and victimization in boys' play groups. J Abnorm Child Psychol 26: 431-440.

18. Cornell DG1, Warren J, Hawk G, Stafford E, Oram G, et al. (1996) Psychopathy in instrumental and reactive violent offenders. J Consult Clin Psychol 64: 783-790.

19. Dempster RJ, Lyon DR, Sullivan LE, Hart SD (1996) Psychopathy and Instrumental Aggression in Violent Offenders. Paper presented at the Annual Meeting of the American Psychological Association, Toronto, Ontario.

20. Kimonis ER, Frick PJ, Fazekas H, Loney BR (2006) Psychopathy, aggression, and the processing of emotional stimuli in non-referred girls and boys. Behav Sci Law 24: 21-37.

21. Frick PJ, Marsee MA (2006) Psychopathy and developmental pathways to antisocial behavior in youth. In C.J. Patrick (Edn.), Handbook of psychopathy, New York: Guilford.

22. Frick PJ (1995) Callous-unemotional traits and conduct problems: A twofactor model of psychopathy in children. Issues in Criminological and Legal Psychology, 1: 47-51.

23. Strickle TR, Kirkpatrick NM, Brush LN (2009) Callous-Unemotional traits and social information processing: Multiple risk factor models for understanding aggressive behavior in antisocial youth. Law Hum Behav, 33: 515-529.

24. Amin N, Foa EB, Coles ME (1998) Negative interpretation bias in social phobia. Behav Res Ther 36: 945-957.

25. Butler G, Mathews A (1983) Cognitive processes in anxiety. Advances in Behaviour Research and Therapy, 5, 51-62.

26. Raine A, Dodge K, Loeber R, Gatzke-Kopp L, Lynam D et al., (2006) The Reactive-Proactive Aggression Questionnaire: Differential Correlates of Reactive and Proactive Aggression in Adolescent Boys. Aggressive Behavior, 32: 159-171. 
Citation: Cima M, Vancleef LMG, Lobbestael J, Cor Meesters, Korebrits A (2014) Don't you Dare Look at me, or else: Negative and Aggressive Interpretation Bias, Callous Unemotional Traits and Type of Aggression. J Child Adolesc Behav 2: 128. doi:10.4172/2375-4494.1000128

Page 9 of 9

27. Cima M, Raine A, Meesters C, Popma A (2013) Validation of the Dutch Reactive Proactive Questionnaire (RPQ): differential Correlates of Reactive and Proactive Aggression from childhood to adulthood. Aggress Behav 39: 99-113.

28. Frick PJ (2003) The Inventory of Callous-Unemotional Traits. Unpublished rating scale, University of New Orleans.

29. Feilhauer J, Cima M, Arntz A, (2012) Assessing callous-unemotional traits across different groups of youths: Further cross-cultural validation of the Inventory of Callous-Unemotional Traits. International Journal of Law and Psychiatry, 35: 251-262.

30. Roose A, Bijttebier P, Decoene S, Claes L, Frick PJ (2010) Assessing the affective features of psychopathy in adolescence: a further validation of the inventory of callous and unemotional traits. Assessment 17: 44-57.

31. Miller JD, Lynam DR (2006) Reactive and proactive aggression: Similarities and differences. Personality and Individual Differences, 41: $1469-1480$.

32. Cima M (2003) Faking Good, Bad, and Ugly; Malingering in forensic psychiatric inpatients. Groeneveldt BV: Landgraaf.

33. Richards A, French CC (1992) An anxiety-related bias in semantic activation when processing threat / neutral homographs. The Quarterly Journal of Experimental Psychology, Section A: Human Experimental Psychology, 45, 503-525.

34. Richards A, French CC, Johnson W, Naparstek J, Williams J (1992) Effects of mood manipulation and anxiety on performance of an emotional Stroop task. Br J Psychol 83 : 479-491.

35. Lilienfeld SO, Andrews BP (1996) Development and preliminary validation of a self-report measure of psychopathic personality traits in noncriminal populations. J Pers Assess 66: 488-524.

36. Neumann CS, Malterer MB, Newman JP (2008) Factor structure of the Psychopathic Personality Inventory (PPI): findings from a large incarcerated sample. Psychol Assess 20: 169-174.

37. Tonnaer F, Cima M, Sijtsma K, Uzieblo K, Lilienfeld S O (2013) Screening for Psychopathy: Validation of the Psychopathic Personality InventoryShort Form with Reference Scores. Journal of Psychopathology and Behavioural Assessment, 35: 153-161.

38. McMahon RJ, Witkiewitz K, Kotler JS; Conduct Problems Prevention Research Group (2010) Predictive validity of callous-unemotional traits measured in early adolescence with respect to multiple antisocial outcomes. J Abnorm Psychol 119: 752-763.

39. Frick PJ, Ray JV, Thornton LC, Kahn RE (2013) Annual Research Review A developmental psychopathology approach to understanding callousunemotional traits in children and adolescents with serious conduct problems. The Journal of Child Psychology and Psychiatry, 1-17
40. Blair RJ, Colledge E, Murray L, Mitchell DG (2001) A selective impairment in the processing of sad and fearful expressions in children with psychopathic tendencies. J Abnorm Child Psychol 29: 491-498.

41. Dadds MR, Perry Y, Hawes DJ, Merz S, Riddell AC, et al. (2006) Attention to the eyes and fear-recognition deficits in child psychopathy. Br J Psychiatry 189: 280-281.

42. Kimonis ER, Frick PJ, Skeem JL, Marsee MA, Cruise K, et al. (2008) Assessing callous-unemotional traits in adolescent offenders: validation of the Inventory of Callous-Unemotional Traits. Int J Law Psychiatry 31: 241-252.

43. Stevens D, Charman T, Blair RJ (2001) Recognition of emotion in facial expressions and vocal tones in children with psychopathic tendencies. J Genet Psychol 162: 201-211.

44. Brugman D, Bink M D (2010) Effects of the EQUIP peer intervention program on self-serving cognitive distortions and recidivism among delinquent male adolescents. Psychology, Crime and Law, 17: 345-358.

45. Cima, M., Korebrits, A., Stams, G.J., \& Bleumer, P. (submitted). Morality in (delinquent) juveniles varying in their levels of psychopathic traits; The relationship between moral behavior, moral cognitions and moral emotions.

46. Crapanzano AM, Frick PJ, Terranova AM (2010) Patterns of physical and relational aggression in a school-based sample of boys and girls. J Abnorm Child Psychol 38: 433-445.

47. Lynam DR, Hoyle RH, Newman JP (2006) The perils of partialling: cautionary tales from aggression and psychopathy. Assessment 13: 328-341.

48. Stickle TR, Marini VA, Thomas JN (2012) Gender differences in psychopathic traits, types, and correlates of aggression among adjudicated youth. J Abnorm Child Psychol 40: 513-525.

49. Blasi A (1980) Bridging moral cognition and moral action: A critical review of the literature. Psychological Bulletin, 88: 1-45.

50. Brugman D (2010) Moral reasoning competence and the moral judgment-action discrepancy in young adolescents. In W.K. Koops, D. Brugman, T.J. Ferguson, \& A.F. Sanders (Eds.), The development of conscience (pp. 119-133). Psychology Press: New York.

51. Breuk R E, Clauser CA, Stams GJ, Slot NW, Doreleijers TA (2007) The validity of questionnaire self-report of psychopathology and parent-child relationship quality in juvenile delinquents with psychiatric disorders. J Adolesc 30: 761-771.

52. Beck A T, Clark D A (1988) Anxiety and depression: An information processing perspective. Anxiety Research, 1: 23-36. 